\title{
Reserva Ecológica do IBGE (Brasília - DF): Flacourtiaceae
}

\author{
Ronaldo Marquete ${ }^{1}$
}

\section{RESUMO}

O presente trabalho foi desenvolvido na Reserva Ecológica do IBGE, onde foi realizado um levantamento das espécies da família Flacourtiaceae representadas na coleção do herbário. Assinalase para esta área a ocorrência de cinco táxons pertencentes aos seguintes gêneros: Xylosma (1), Lacistema (1) e Casearia (3).

O estudo taxonômico das espécies foi caracterizado nas descrições, na elaboração da chave analítica, observações de campo efetuadas durante as coletas e a sua ocorrência nos ambientes das savanas. Palavras-chaves: Flacourtiaceae, Savanas, Brasília, Distrito Federal, Brasil.

\begin{abstract}
The present work was developed in the Ecological Reserve of the IBGE-DF, where was made a survey of the species of the family Flacourtiaceae represented in the collection of the herbarium, it is marked for this area the occurrence of five taxons belonging to the following genera: Xylosma (1), Lacistema (1) and Casearia (3).

The taxonomyc study of the species was characterized in the discriptions, in the elaboration of the analytic key, field observations made during the collections and the distribution of the species in the environments of the savannas.
\end{abstract}

Keywords: Flacourtiaceae, Savannas, Brasília, Distrito Federal, Brazil.

\section{INTRODUÇÃO}

A Reserva Ecológica do IBGE (RECOR), constitui-se em uma das Unidades de Conservação do bioma Cerrado, localizase no Centro-Oeste brasileiro a $33 \mathrm{~km}$ ao sul de Brasília, na BR-251, nas seguintes coordenadas geográficas: $15^{\circ} 56^{\prime} 41^{\prime \prime} \mathrm{S}$ e $47^{\circ}$ 53' 07" W GRW. Sua área é cerca de 1300 ha, e sua altitude varia de 1048 a 1160 m s.m., apresentando um relevo suave e típico de chapadas, com desníveis representados apenas pelos vãos da rede de drenagem (Pereira et al., 1989 e 1993).

A RECOR apresenta os principais tipos de vegetação do Planalto Central: Cerradão, cerrado, campos (sujo e limpo) e matas ciliares (brejos e veredas), Pereira et al. (1989 e 1993). O trabalho visa ampliar o conhecimento florístico e taxonômico das espécies de Flacourtiaceae nesta reserva. A família está representada na área, até o momento, por 5 espécies subordinadas a 3 gêneros: Casearia altiplanensis Sleumer, $C$. decandra Jacquin, C. sylvestris Swartz, Lacistema hasslerianum Chodat (sensu Sleumer) Xylosma pseudosalzmannii Sleumer.

Tais espécies são predominantes na vegetação de mata ciliar exceto $C$. sylvestris que ocorre em todos os ambientes e $C$. altiplanensis que é restrita ao cerrado.

$\mathrm{O}$ presente estudo vem reforçar a

\footnotetext{
${ }^{1}$ Fundação Instituto Brasileiro de Geografia e Estatística - IBGE/JBRJ.
} e-mail: rmarquet@jbrj.gov.br 
importância do conhecimento científico para fortalecer as bases de sua conservação e preservação. Considerando que o avanço antrópico é muito mais rápido, ampliando suas fronteiras para agricultura, mineração, extração, pecuária e etc. O cerrado é o mais rico ecossistema entre as savanas do mundo (Alho \& Martins, 1995). É preciso melhor conhecer este potencial, representado por uma grande riqueza de espécies.

\section{METODOLOGIA}

Os estudos taxonômicos foram realizados através da análise morfológica dos táxons pertencentes à família Flacourtiaceae, possibilitando a identificação das espécies, os dados referentes ao habitat, dados floração de e frutificação, freqüência, distribuição geográfica, nome vulgar e sua ocorrência nas diferentes fisionomias, baseiam-se nas etiquetas dos materiais examinados e nas observações de campo.

Em nosso trabalho, revisamos todos os exemplares armazenados no Herbário do IBGE/DF, Universidade Federal de Brasília (UB), Jardim Botânico de Brasília e do Jardim Botânico do Rio de Janeiro (RB). Foram realizadas excursões a RECOR no período de 1995 a 1997 para observações dos táxons em seu ambiente, bem como a coleta de material botânico. As descrições, observações e ilustrações foram realizadas apenas com base no material ocorrente na área. Para detalhar as ilustrações utilizou- se o estereomicroscópio equipado com câmara clara. Para análise da nervação foliar de $C$. sylvestris diafanizou-se com Hidróxido de sódio a $5 \%$, para coloração usou-se safranina a $50 \%$.

\section{RESULTADOS}

Esta família apresenta grande distribuição nas áreas tropicais e subtropicais com cerca de 800 espécies subordinados a 86 gêneros. Ocorre também na zona temperada, com menor representatividade. Nos neotrópicos apresenta cerca de 275 espécies (Sleumer, 1984). Para o Brasil encontramos as espécies distribuídas pelos diferentes ecossistemas, com grande capacidade de adaptação ao meio.

São árvores, arbustos ou subarbustos lenhosos. Folhas persistentes às vezes decíduas, alternas, inteiras, simples, peninérveas, geralmente denteadas, lâminas lanceoladas, oblongo-lanceoladas ou lanceolado-ovadas; pecíolos delgado a espessado; estípulas 2, foliáceas, caducas ou persistentes. Inflorescências axilares, fasciculadas ou em espigas, brácteas e bractéolas pequenas escamiformes. Flores actinomorfas, monoclamídeas a diclamídeas, hermafroditas ou unisexuadas, pedicelos muitas vezes articulados; sépalas persistentes; estames de 1 a muitos, anteras rimosas; ovário súpero, unilocular, tricarpelar, placentação parietal. Fruto cápsular ou bacáceo.

\section{CHAVE PARA OS GÊNEROS DE FLACOURTIACEAE}

1 . Flores dióicas. Fruto bacáceo. 3. Xylosma (Xylosma pseudosalzmannii)

1'. Flores hermafroditas. Fruto capsular ...2

2 . Inflorescência em espiga, 1 estame 2. Lacistema

2'. Inflorescência fasciculada, 10 estames (Lacistema hasslerianum) 1. Casearia 
1. Casearia N. J. Jacquin, Enum. Syst. Pl. Carib. 4:21.1760; Stirp Amer. Hist. 132, t.85.1763; Sleumer, Fl. Neotropica 22:280.1980.

Árvores, arbustos ou subarbustos, tronco de casca lisa a fissurada, ramos cilíndricos, patentes, delgados, levemente flexuosos a eretos, de cor acinzentada ou amarronzada. Folhas dísticas, estípulas de ovadas a subuladas, caducas ou persistentes, com ou sem pontuações e traços translúcidos, pecíolo subcilíndrico a cilíndrico. Inflorescências fasciculadas, multifloras ou paucifloras. Flores hermafroditas, pequenas, pedicelos não articulados a articulados acima da base, esverdeadas, sépalas 5, soldadas na base, reflexas na antese. Estames 10, unisseriados, perigíneos; filetes filiformes, livres, na base conados ao disco, anteras globosas. Lobos do disco claviformes, alternados com os estames. Ovário séssil, estilete inteiro, estigma simples ou trífido no ápice, globoso ou capitado. Fruto cápsula, globosa, trivalvar.

\section{CHAVE PARA AS ESPÉCIES DE CASEARIA}

1. Subarbusto com vários caules saindo do xilopódio, folhas coriáceas, estípulas subuladas, anteras com glândulas crassas e tricomas eretos 1.Casearia altiplanensis 1'. Árvore ou arbusto, folhas membranáceas a cartáceas, estípulas caducas, sem glândula apical, sem tricomas ...2 2 . Árvore com folhas membranáceas, decíduas na floração, anteras sem glândulas, estigma capitado. 2. Casearia decandra

2'. Arbusto com folhas cartáceas, persistentes na floração, anteras com glândulas glabras, estigma trilobado, globoso. 3.Casearia sylvestris

\section{Casearia altiplanensis Sleumer} Sleumer, Fl. Neotropica 22:319.1980. (Fig. 1)

Subarbusto lenhoso com ca. de $35 \mathrm{~cm}$ de alt.; raízes espessadas em xilopódio, com vários caules saindo da base; casca lisa, cor marrom, ramos eretos, finos, glabrescentes a puberulentos, pardo-marrons. Estípulas subuladas, cor amarela, persistentes, $3-7 \mathrm{~mm}$ compr. Folhas persistentes, pecíolo glabro, 1 $2 \mathrm{~mm}$ compr.; lâminas oblongo-lanceoladas a lanceoladas, ápice acuminado, com apículo de 1 - 2mm compr., base de obtusa a cuneada, margem mucronado-serrada com dentes de 0.5 - 0.8mm compr., subcoriáceas a coriáceas, discolores verdes, pontuações translúcidas, glabras, nítidas na face adaxial e opacas na abaxial, 1.5 - 5cm compr. x 1.5 - $2.3 \mathrm{~cm}$ larg., nervuras secundárias ascendentes, 4 - 8 pares, muito proeminentes na face abaxial e pouco na adaxial, reticulado das veias e vênulas denso na face abaxial (em alguns exemplares ficam pouco proeminentes). Inflorescências subsésseis, tomentosas a velutinas; flores 2 -
6; bráctea lanceolado-ovada, (1.5) $2 \mathrm{~mm}$ compr. x $2 \mathrm{~mm}$ larg., tomentosa a velutina; pedicelos cilíndricos, tomentosos a velutinos, 1 - 2mm compr.; botões ovados a subglobosos, sépalas 5 , unidas na base, subovadas, oblongo-ovadas, cor alvo-esverdeada, creme a rósea, interna glabras e externas tomentoso-velutinas, $6 \mathrm{~mm}$ compr. x 2.5mm - 5mm larg.; estames 10 , filetes cilíndricos, pubescentes e glabros para o ápice, ca. $3 \mathrm{~mm}$ compr.; antera com glândula apical crassa e provida de tricomas eretos. Lobos do disco clavados, cor amarela a alvacenta quando secos, tomentoso-vilosos, 2 -2,5mm compr.; ovário ovado-alongado, viloso, tricarpelar; estilete cilíndrico, com tricomas apressos e hirsutos; estigma capitado, tricomas eretos. Frutos ovado-elipsóides, amarelados quando secos, base glabra, a parte superior pubescente, intensamente alvo-amarelada, 7 9mm compr. x 4 - 6mm larg.; sementes ovadas a elipsóides, $7 \mathrm{~mm}-1 \mathrm{~cm}$ compr. x $6-7 \mathrm{~mm}$ larg., quando secas marrons. Sépalas persistentes. 


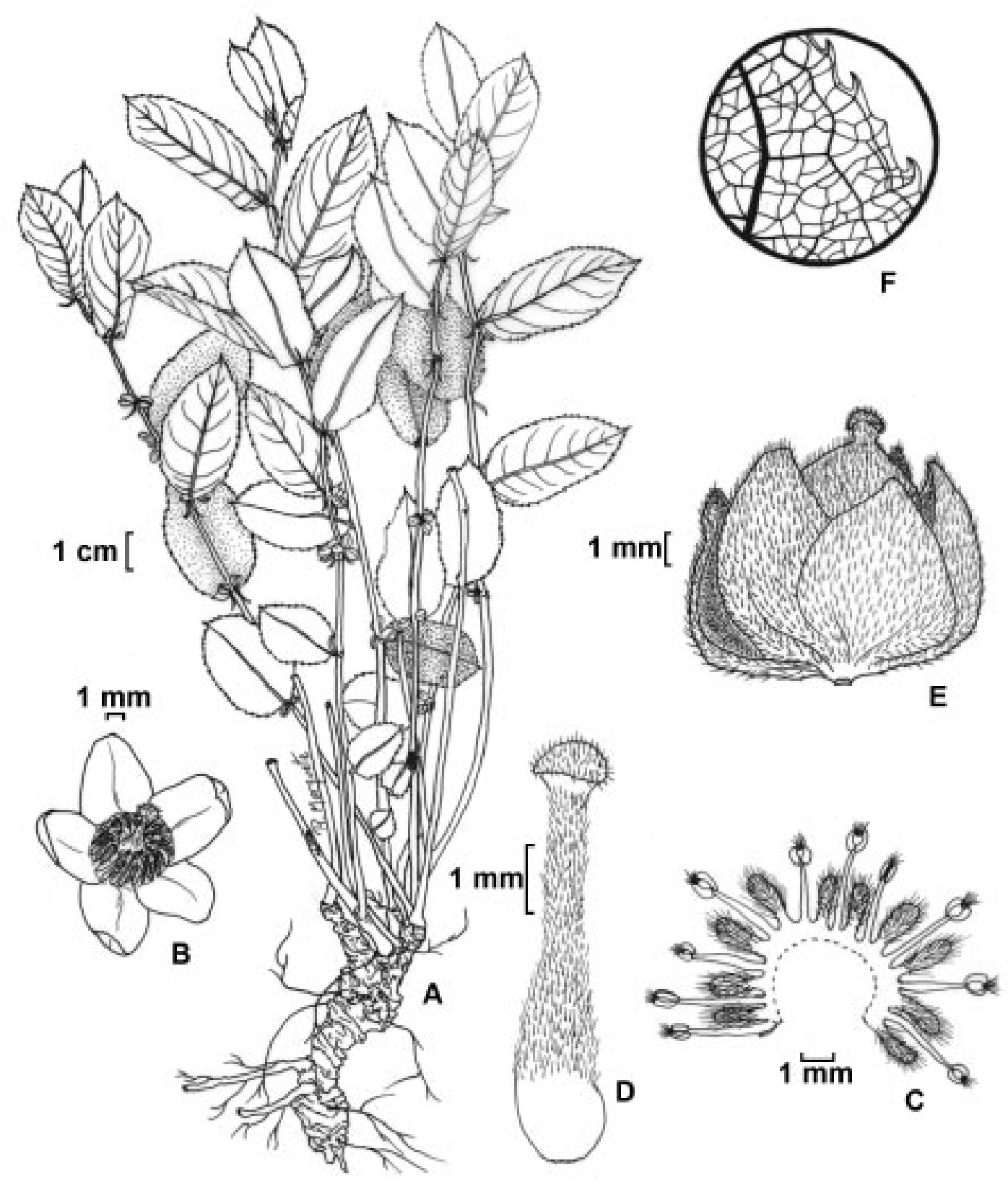

Figura 1 - Casearia altiplanensis Sleumer. A. Hábito; B. Flor; C. Detalhe do disco e estames; D. Gineceu; E. Fruto jovem; F. Detalhe da rede de nervação e aspecto do bordo. 
Comentários.: As pontuações translúcidas em alguns exemplares são mais aparentes em toda a lâmina foliar, já em outras folhas somente são notadas nas margens, ápice e base. Existem indivíduos com folhas coriáceas que quase não observamos estes pontos.

Material examinado: Brasil. Brasília, Distrito Federal: RECOR, Fonseca, M.L. 565 (IBGE); Heringer, E.P. \& al. 5590 (IBGE); Aparecida da Silva, M. \& al 244 (IBGE); Marquete, R. $\&$ al 2604, 2935, 2848, 2140, 2142 (IBGE); Proença, C. 740 (IBGE).

Distribuição Geográfica: Brasil, nos estados de Goiás e Brasília. Ocorre com freqüência na RECOR, principalmente em áreas abertas. Tipo de vegetação e floração e frutificação: Ocorre em savana (cerrado) e floresce em setembro e outubro, frutos a partir de setembro a dezembro.

\section{Casearia decandra Jacquin}

Jacquin, Enum. Syst. Pl. Carib. 21. 1760; Sel. Stirp. Amer. Hist. 133, t. 85. 1763; Urban, Symb. Antill. 4:420.1910; Sleumer, Fl. Neotropica 22:390.1980; Fl. Ilustr. Catar. 1:7887.1984.

Árvore com ca. $5 \mathrm{~m}$ de alt.; tronco com $10 \mathrm{~cm}$ de DAP e casca marrom; ramos puberulentos no ápice e glabrescentes para a base, cor marrom, com lenticelas esparsas. Estípulas não vistas. Folhas decíduas com pecíolo puberulento, subcilíndrico, delgado, 2 $5 \mathrm{~mm}$ compr.; lâminas lanceoladas a oblongolanceoladas, ápice longo-acuminado a acuminado, base cuneada a levemente desiguais, margem serrada a crenada com dentes de ca. $0.5 \mathrm{~mm}$, suave revolutos com poucos dentes na base, membranáceas, discolores verdes, pardacentas a amareladas, quando secas com poucos pontos translúcidos dispersos na lâmina, nervura primária puberulenta e secundárias glabrescentes , 6 $9 \mathrm{~cm}$ compr. x $2.5-4.1 \mathrm{~cm}$ larg., 4 - 7 pares de nervuras ascendentes, mais proeminentes na face abaxial, reticulado das veias e vênulas laxas e pouco proeminente em ambas as faces. Inflorescências sésseis, com tricomas tomentosos a velutinos; brácteas de ca. $1.5 \mathrm{~mm}$ compr. x 1 - 2mm larg., ovadas côncavas, numerosas, escamosas, na face externa tomentosa e rufa, interna com tricomas esparsos da metade para o ápice; pedicelos cilíndricos, articulados na base, tomentosos, ca. $2.5 \mathrm{~mm}$ compr.; botões obovado-oblongos a oblongo-ovados, tormentosos a velutinos, 4 - 8 flores por inflorescência, sépalas 5, curtamente soldadas na base, oblongas a lanceoladas, esverdeadas, face externa tomentosa, ca. 3 mm compr. x 1 -2 mm larg.; estames 10, filetes desiguais, tomentosos até a metade e glabros para o ápice, 0.5 - $1 \mathrm{~mm}$ compr.; anteras amarelas quando secas, glabras; lobos do disco oblongo-clavados, amarelo-escuros quando secos, esparso tomentosos, ca. $0.5 \mathrm{~mm}$ compr.; ovário ovado a oblongo-ovado, viloso; estilete curto, viloso; estigma capitado.

Comentários.: Estípulas não observadas nas plantas adultas, sendo mais facilmente encontradas nos ramos com folhas jovens. Flores não aromáticas. Esta espécie não foi recoletada na área em estudo.

Material examinado: Brasil. Brasília, Distrito Federal: RECOR, Aparecida da Silva, M. \& Lopes, A. C. 798 (IBGE).

Distribuição Geográfica: Honduras, Panamá, nas Antilhas, Colômbia, Venezuela, Trindade, Guiana, Suriname, Guiana Francesa, Equador, Peru, no Brasil: (Amazonas, Roraima, Pernambuco, Mato Grosso, Goiás, Brasília, Minas Gerais, São Paulo, Rio de Janeiro, Paraná, Santa Catarina, Rio Grande do Sul), Paraguai, Uruguai e Argentina.

Tipo de vegetação e floração e frutificação: Ocorre em mata ciliar; botões no final de agosto.

\section{Casearia sylvestris Swartz}

Swartz, Fl. Ind. Occid. 2:752.1798; Willdenow, Sp. Pl. 2:628.1799; DC, Prodr. 2:49.1825; Sprengel, Syst. 2:355.1825; Sleumer, Fl. Neotropica 22:390.1980; Fl. Ilustr. Catar. 1:7887.1984.

(Fig. 2.)

Arbustos de $1 \mathrm{a} 3 \mathrm{~m}$ de alt.; tronco de casca fissurada, amarronzada a acinzentada. 
Ramos patentes, delgados, flexuosos, glabros na base a puberulentos no ápice, marrons a avermelhados, nas partes adultas cinzacorticosas, \pm lenticelados. Estípulas ovadas, ca. $1 \mathrm{~mm}$ compr. Folhas persistentes em geral, com grande dimorfismo foliar, de acordo com as condições ecológicas, em geral estreitas; pecíolo glabro ou puberulento, delgado, 3 - 8mm compr., lâminas lanceolado-ovadas, oblongolanceoladas a lanceoladas, ápice curto a longoacuminado a falcado, base freqüentemente assimétrica, cuneada ou obtusa, margem mucronado-serrado a serrado, cartáceas, concolor verdes, nítidas na face adaxial quando frescas, com pontuações e traços translúcidos densos, glabras, raro curto-pubescente na face abaxial, sempre sobre as nervuras central e secundárias, (3) $6-11 \mathrm{~cm}$ compr. x (1)2 $3.2(4.2) \mathrm{cm}$ larg., nervuras secundárias ascendentes de $5-8$ pares, proeminentes na face abaxial, reticulado das veias e vênulas muito densa na face abaxial, pouco proeminentes na face adaxial. Inflorescências sésseis, variáveis na densidade e no tomento, em geral multifloras; brácteas pequenas, pouco pubescentes; pedicelos delgados, articulados próximo ou abaixo do centro (meio), pubescentes, 2 - 4(5)mm compr. Flores com aroma adocicado; botões de forma obovada a globosa; sépalas 5, levemente unidas na base, largo ovada, esverdeadas, cremes ou alvoamareladas, glabras a tomentelas no dorso, ciliados, ca. $2 \mathrm{~mm}$ compr.; estames 10 , filetes livres, nos botões pouco desiguais, de glabros a glabrescentes no ápice e denso para a base, 1 - $1.5 \mathrm{~mm}$ compr.; anteras com uma pequena glândula apical. Lobos do disco unidos na base dos filetes, alvacentos, densamente pilosos, ca. $1 \mathrm{~mm}$ compr.; ovário ovóide-obtusangular, glabro na base e com tricomas esparso no ápice, estilete delgado, inteiro, esparso piloso; estigma globoso, trilobado, piloso a glabrescente. Fruto ovóide, globoso a obtusangular, quando imaturos verde escuro até avermelhado, glabro a tênue piloso no ápice, 3 - 7mm compr. x 5mm larg.; 1 - 4 (7) sementes, 3 - 4mm compr. x 2 - 3 larg., elipsóides, lisas, com arilo alaranjado, quando seco marrom. Frutos e sementes observados em fase jovem, sépalas persistentes circundam a cápsula.

Comentários: Geralmente os ramos apresentam a folha da base diferenciada das demais, tanto na forma e tamanho (bem menor). Em alguns exemplares os ramos da base da planta apresentam folhas maiores que as dos ramos superiores. Esta espécie apresenta grande variação em relação ao tamanho, forma, consistência das folhas e pilosidade dos ramos e das inflorescências. Sleumer (1980), apresenta duas variedades para esta espécie, $C$. sylvestre var. sylvestre e var. lingua, mas encontrou formas intermediárias. Com base na diafanização, de algumas folhas do material estudado, realmente verificou-se poucas diferenças na forma e na venação da rede de veias e vênulas, porem neste trabalho não considerou-se estas variedades, tendo em vista a dificuldade em delimitar estes táxons. Estudos posteriores deverão ser feitos para melhor definir a posição destes táxons. Espécie muito freqüente na área, encontrada em vários ambientes.

Uso medicinal: As folhas e raízes são depurativas do sangue, moléstias da pele e no combate à sífilis (Siqueira,1981,1988). Utilizada em forma de chás. Também o suco das folhas é usado contra mordedura de cobras, Segundo Torres \& Yamamoto (1986) e comprovado no trabalho de Borges et al. (1997).

Material examinado: Brasil. Brasília, Distrito Federal: RECOR, Heringer, E.P. \& al. 124 (IBGE); Marquete, R. \& al. 2282, 2283, 2284, 2285, 2286, 2606 (IBGE); Azevedo, M.L.M. \& al. 304, 915, 923 (IBGE); Pereira, B.A.S. 741, 1033 (IBGE); Aparecida da Silva, M. 815, 2715 (IBGE); Oliveira, F.C.A . \& al. 449, (IBGE); Alvarenga, D. 315 (IBGE), Landim de Souza, M.F. 54 (IBGE).

Distribuição Geográfica: Desde o México até a Argentina. No Brasil ocorre nos estados: Amazonas, Roraima, Pará, Amapá, Maranhão, Piauí, Ceará, Rio Grande do Norte, Paraíba, Pernambuco, Rondônia, Mato Grosso, Goiás, Brasília, Bahia, Alagoas, Minas Gerais, Espírito 


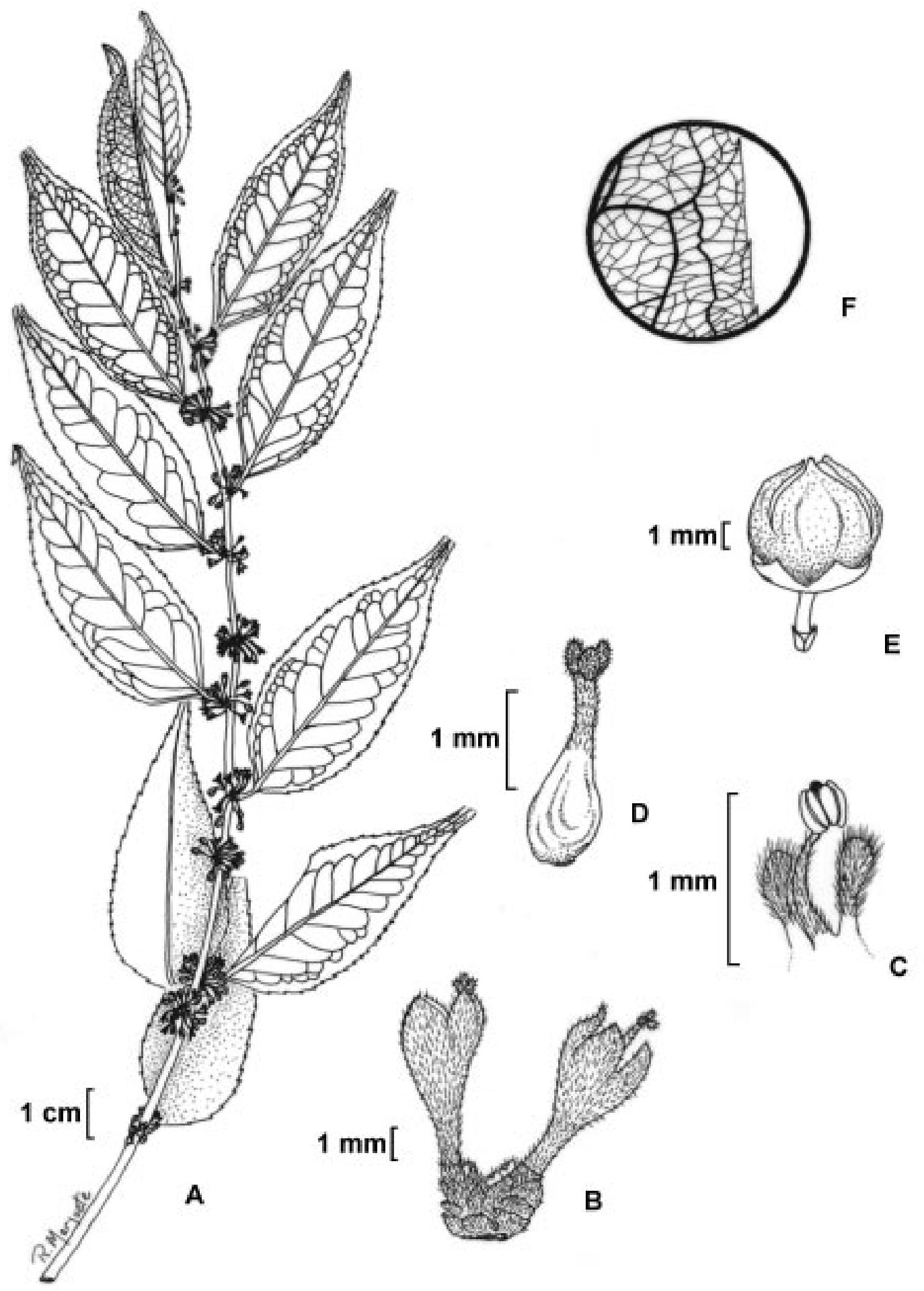

Figura 2 - Casearia sylvestris Swartz. A. Hábito; B. Flor; C. Detalhe do disco e estame; D. Gineceu; E. Fruto; F. Detalhe da rede de nervação e aspecto do bordo. 
Santo, São Paulo, Rio de Janeiro, Paraná, Santa Catarina, Rio grande do Sul.

Tipo de vegetação e floração e frutificação: Ocorre em cerrado ralo, savana florestada (Cerradão descaracterizado), savana arborizada (cerrado), mata ciliar. Apresenta botões e flores em julho, agosto, setembro e início de frutificação em agosto e outubro.

2. Lacistema Swartz, Prodr. Veg. Ind. Occ. 12.1788; Martius, Nov. Gen. Sp. 1:154, t.94,95.1824; Schnilzlein In Martius, Fl. Brasiliensis 4(1):281.1857; Sleumer, Fl. Neotropica 22:183.1980; Sleumer, Fl. Ilustr. Catar. 1:45.1984.

Arbusto com ramos cilíndricos, delgados. Folhas persistentes, estípulas persistentes no ápice dos ramos; pecioladas; estípulas com a parte central pilosas na face externa. Inflorescências multifloras, globosas quando jovens (botão), cilíndricas na maturidade, glabras. Flores hermafroditas, botões subglobosos, glabros. Sépalas 4, lanceoladas, glabras. Estames 1, filete livre, antera rimosa, globosa. Disco em forma de taça membranácea. Ovário glabro, estilete curto, estigma tripartido. Fruto cápsula loculicida, subelíptica a elipsóide, glabra, curtamente pedunculada.

Lacistema hasslerianum Chodat

Chodat, Bull. Herb. Boiss. 2(3):394.1903; Chirtoiu, Bull. Soc. Bot. Genève 2(10):344, f.18.1919; Sleumer, Fl. Neotropica 22:192.1980; Fl. Ilustr. Catar. 1:47.1984. (Fig. 3)

Arbusto de 2 a $3.5 \mathrm{~m}$ de alt.; tronco com casca lisa, acinzentada, ramos delgados, glabros, acinzentados. Estípulas subuladas, 4 7 (9)mm compr. x $2 \mathrm{~mm}$ larg. Folhas com pecíolo glabro, 4 - 9mm compr.; lâminas lanceoladas a levemente oblongo-lanceoladas, ápice acuminado, base cuneada (algumas folhas da ponta dos ramos apresentam a base subassimétrica), margem crenada a subserrada para o ápice da lâmina e para base inteira, cartáceas, concolor verdes e opacas em ambas as faces, tricomas esparsos na superfície abaxial, na maturidade ficam glabrescentes, 5.5 - 12.8 (15)cm compr. x 1.9 - 4.5 (5.8)cm larg., nervuras secundárias ascendentes de 4 - 6 pares, proeminentes na face abaxial, reticulado das veias e vênulas laxo, pouco proeminentes na face adaxial; Inflorescência em espigas com 6 - 11 (15) espigas por axila, 4 - 8mm compr., brácteas côncavas; botão com ca. $1 \mathrm{~mm}$ compr.; sépalas 4, livres, esverdeadas, $1 \mathrm{~mm}$ compr.; estame com filete aplanado, saindo da base do ovário; antera com as rimas voltadas para o ovário e para baixo, lobo do disco glabro, ca. $0.5 \mathrm{~mm}$ compr.; ovário ovado, glabro; estilete curto a séssil, estigma agudo e ereto. Fruto cor vermelha, $7 \mathrm{~mm}$ compr. x $6 \mathrm{~mm}$ larg, pedúnculo $1 \mathrm{~mm}$ compr.; 1 semente, $6 \mathrm{~mm}$ compr. $\mathrm{x} 3.5 \mathrm{~mm}$ larg., subglobosa a ovada, lisa, quando seca vermelho-amarronzada; embrião reto. Sépalas persistentes na base do pedúnculo.

Comentários: Neste trabalho adota-se Sleumer 1980, que trata Lacistema como pertencente a família Flacourtiaceae. Espécie restrita as áreas de mata, sendo pouco frequiente. Esta também não foi recoletado.

Material examinado: Brasil. Brasília, Distrito Federal: RECOR, Azevedo, M.L.M. \& al. 260 (IBGE); Mendonça, R.C. 248 (IBGE); Pereira, B.A.S. 528, 573, 621 (IBGE); Alvarenga, D. \& al. 390 (IBGE); Heringer, E.P. 1555 (IBGE)

Distribuição Geográfica: No Brasil nos estados Mato Grosso, Goiás, Brasília, Minas Gerais, São Paulo, Paraná. Paraguai e Argentina.

Tipo de vegetação e floração e frutificação: Ocorre em mata ciliar, margem da mata com botões em maio e floresce a partir de agosto e frutifica em setembro.

3. Xylosma G. Forster, Fl. Ins. Austr. Prodr. 72. 1986, nom. conserv.; Benth. et Hook. Gen. Pl. 1:128.1862; Eichler In Martius, Fl. Brasiliensis. 13(1):443.1871; Gilg. In E.P. Planzenf. 2(21):433.1925; Sleumer, Fl. Neotropica 22:128.1980; Sleumer, Fl. Ilustr. Catar., 1:25.1984.

Árvore ou arbusto, dióico, em geral armados com espinhos até nos ramos. Folhas peninérveas, raramente com margem inteira, 


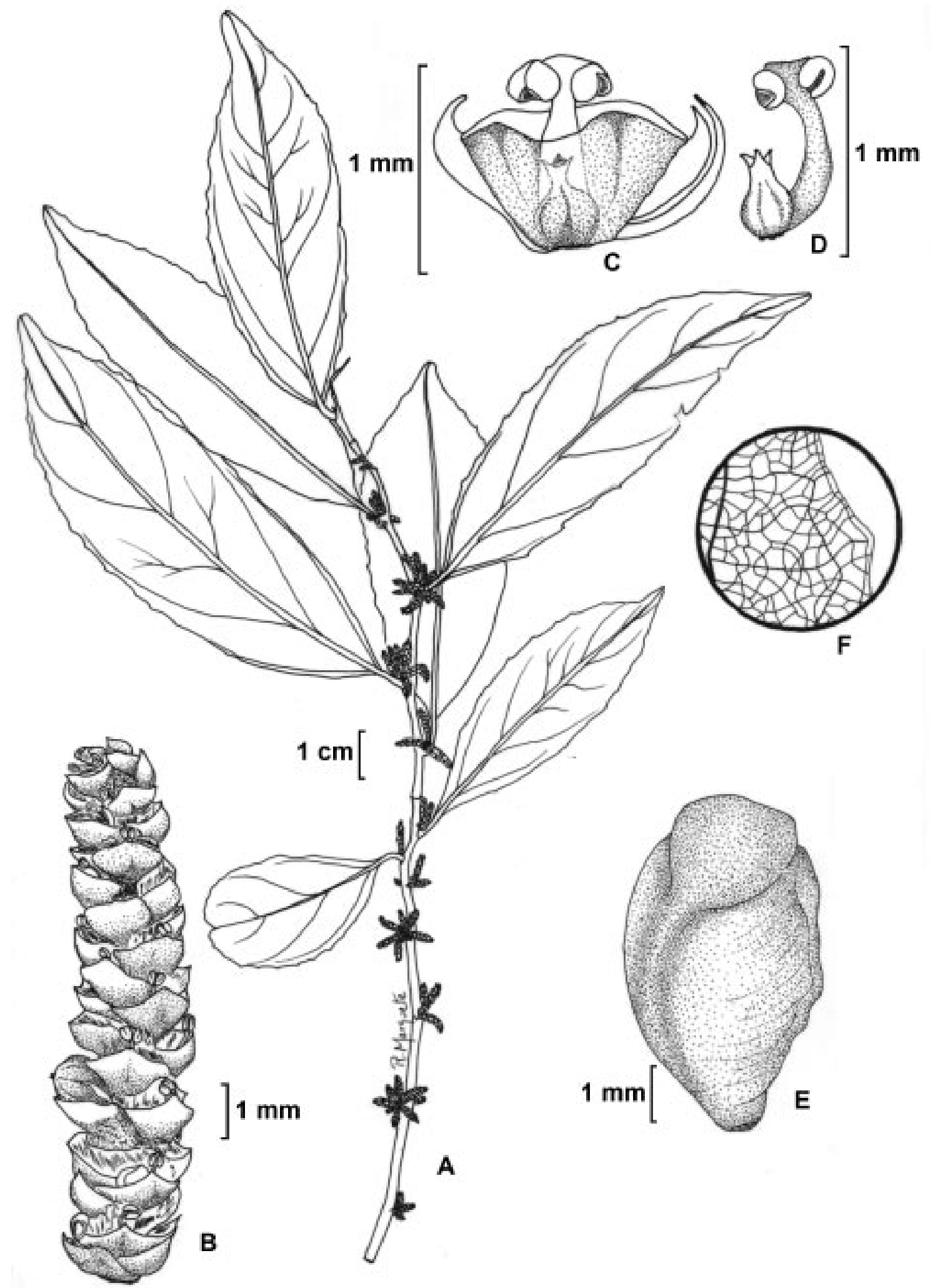

Figura 3 - Lacistema hasslerianum Chodat. A. Hábito; B. Inflorescência; C. Flor; D. Androceu e gineceu; E. Semente; F. Detalhe da rede de nervação e aspecto do bordo. 
pecíolo cilíndrico. Inflorescências, fasciculadas, brácteas côncavas, 1.5 - 2mm compr., pilosas na margem (sendo mais denso no ápice); pedicelos cilíndricos, delgados, articulados e pubescentes próximo a base, 4 $5 \mathrm{~mm}$ compr.; disco extra estaminal, glabro, em forma de anel, ca. $0.5 \mathrm{~mm}$ compr.; flores masculinas de anteras rimosas, globosas, ditecas, filetes cilíndricos, livres, sépalas 4 , flores femininas com 5 - 6 sépalas, livres, disco levemente lobado no ápice e soldado na base, forma de anel. Fruto baga, esférica, glabra.

Xylosma pseudosalzmannii Sleumer, Lilloa 26:44.1953; Fl. Neotropica 22:170.1980; Fl. Ilustr. Catar. 1:33.1984.

(Fig. 4)

Árvore (jovem com ca. $3.80 \mathrm{~m}$ de alt.) ou arbusto ca. $2.5 \mathrm{~m}$ de alt.; tronco com casca lisa, marrom, às vezes com espinhos; ramos finos, cilíndricos, pubérulos no ápice e glabrescentes para a base, amarronzados, lenticelados. Estípulas não vistas. Folhas persistentes, pecíolo pubescente, delgado, 2 $9 \mathrm{~mm}$ compr.; lâminas lanceoladas a largo lanceoladas, ápice curto acuminado a acuminado, base cuneada, margem mucronado-serrada (levemente revoluta), cartáceas, discolores verdes, glabras em ambas as faces, (3.5) 6.6 - $11 \mathrm{~cm}$ compr. x (2) 3 - $4.7 \mathrm{~cm}$ larg.; nervuras secundárias ascendentes, 5 - 8 pares, proeminentes na face abaxial, reticulado das veias e vênulas laxo e pouco proeminentes na face adaxial;. Inflorescências sésseis. Flores masculinas 5 6 , sépalas 4 , curtamente unidas na base, ovadas, esverdeadas, esparso pilosas nas margens, ca. $1.9 \mathrm{~mm}$ compr.; estames 14 , filetes curtos, cilíndricos, ca. 1mm compr., glabros. Lobo do disco curto e externo aos filetes, esverdeado. Flores femininas 4 - 6; brácteas côncavas, ca. $1.5 \mathrm{~mm}$ compr., pilosas nas margens pedicelos cilíndricos, delgados, articulados e pubescentes próximo à base, 4 $5 \mathrm{~mm}$ compr.; sépalas ovadas, esverdeadas, esparso pilosas nas margens, ca. $2 \mathrm{~mm}$ compr.; disco esverdeado, glabro, $0.5 \mathrm{~mm}$ compr.; estilete curto, estigma trífido. Fruto quando jovem esverdeado, maduro vermelho escuro, ca. $6 \mathrm{~mm}$ compr. x ca. $6 \mathrm{~mm}$ larg.; 4 - 7 sementes, quando secas marrons; estilete e estigma observados nos frutos imaturos; sépalas persistentes.

Comentários: Esta espécie não foi reencontrada, e é restrita à região de mata. Trata-se de nova ocorrência para Brasília, sendo mais freqüente nas regiões sudeste e sul.

Material examinado: Brasil. Brasília, Distrito Federal: RECOR, Azevedo, M.L.M. \& al. 285 (IBGE); Pereira, B.A .S. 626 (IBGE).

Distribuição Geográfica: Brasil nos estados Brasília, São Paulo, Paraná, Santa Catarina, Rio Grande do Sul. Paraguai e Argentina.

Tipo de vegetação e floração e frutificação: Ocorre em mata ciliar e floresce em julho e frutifica em agosto.

\section{CONCLUSÃO}

A Reserva Ecológica do IBGE, localiza-se dentro do Bioma Cerrado e é uma área que acolhe em seus 1.360 hectares todas as faciações do Cerrado. Para família Flacourtiaceae colecionada na RECOR, encontramos três gêneros subordinados a cinco espécies, sendo C. altiplanensis descrita por Sleumer (1980), endêmica deste ecossistema. Esta informação foi confirmada com os levantamentos elaborados nos herbários do Centro-Oeste e através de expedições realizadas nas áreas de vegetação de cerrado, onde somente foi localizada para alguns pontos de Goiás e Brasília.

C. decandra e $C$. sylvestris, são espécies de ampla distribuição geográfica, ocorrendo nos vários outros tipos de vegetação dos neotrópicos. A espécie $C$. sylvestris é a que melhor se adapta ao habitat, variando seu porte e morfologia foliar de acordo com as condições ecológicas.

Segundo Sleumer (1984), Lacistema hasslerianum ocorre em regiões de floresta e cerrado, em baixas altitudes e sua distribuição vai da região Centro-Oeste até o Sul do Brasil, chegando ao Paraguai e Argentina.

A espécie Xylosma pseudosalzmannii 


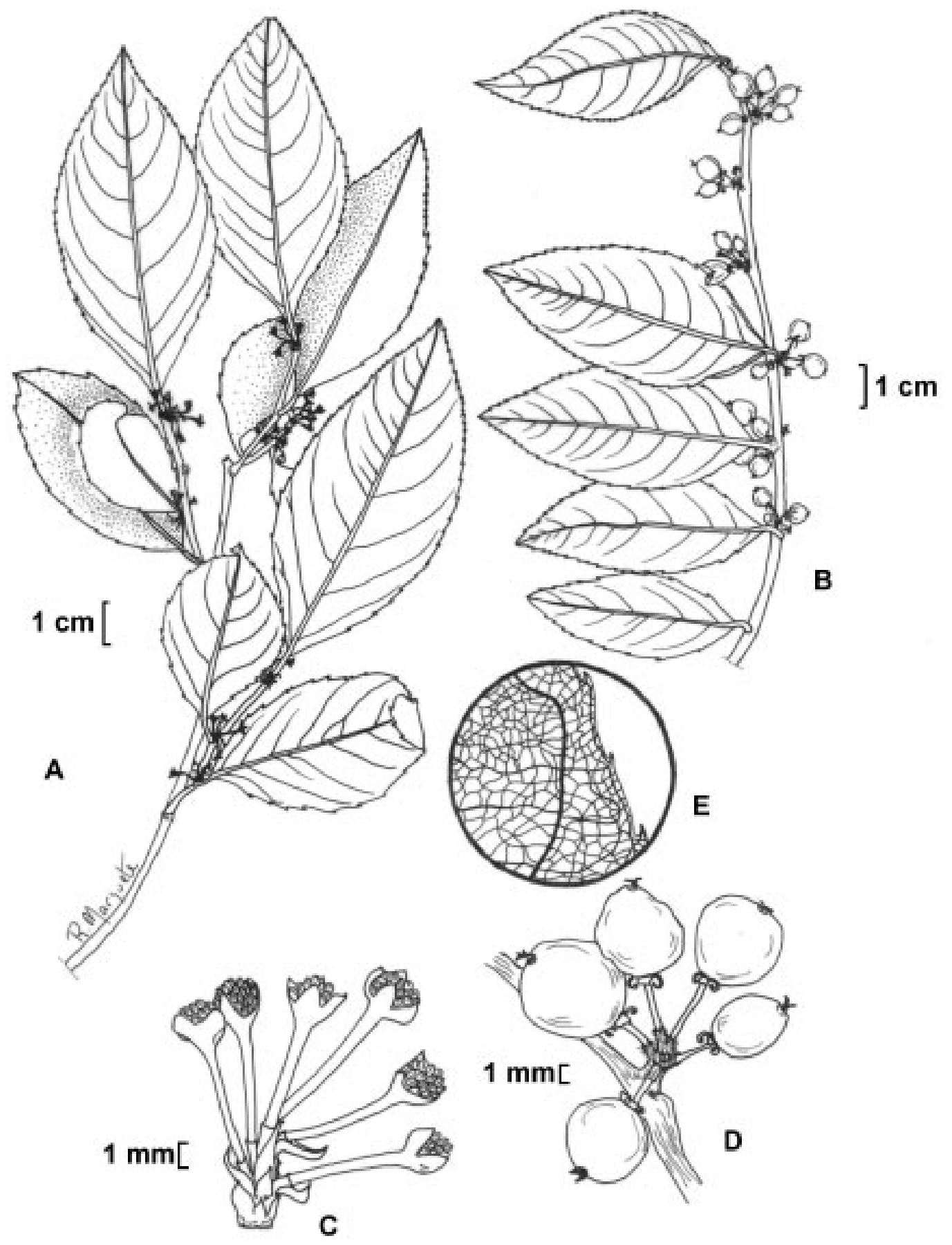

Figura 4 - Xilosma pseudosalzmannii Sleumer. A. Hábito planta masculina; B. Hábito planta feminina; C. Flor masculina; D. Flor feminina com frutos jovens; E. Detalhe da rede de nervação e aspecto do bordo. 
é também característica de mata ciliar e borda de mata, é mais freqüente no interior dos subbosques onde a luminosidade é menor e existe uma maior umidade (Sleumer, 1984). Esta espécie é citada como nova ocorrência para Brasília.

\section{AGRADECIMENTOS}

Ao Instituto Brasileiro de Geografia e Estatística (IBGE) em especial a Profa. Roberta C. Mendonça, sua equipe e demais funcionários da Reserva Ecológica do IBGE Brasília pelo apoio concedido.

Ao Instituto de Pesquisas Jardim Botânico do Rio de Janeiro pelas instalações concedidas na Área de Botânica Sistemática para realização deste trabalho.

Aos professores Dr. Tarciso Filgueiras, Ms. Angela M. S. da Fonseca Vaz e Nilda Marquete F. da Silva pela orientação, companheirismo, apoio e valiosas sugestões no texto.

\section{REFERÊNCIAS BIBLIOGRÁFICAS}

Alho, C. J. R \& Martins, E. de S. (Eds.). 1995.

De Grão em Grão, o Cerrado perde Espaço (Cerrado - Impactos do Processo de Ocupação). WWF \& PRO-CER. 66p. il.

Borges, M. H. 1997. Ação antipeçonhenta do extrato vegetal de Casearia sylvestris (Inibição da atividade fosfolipase A2, hemorrágica e miotóxica de venenos animais pelo extrato de Casearia sylvestris (FLACOURTIACEAE). In: http://www.biotecnologia.com.br. Biotecnologia Ciência \& Desenvolvimento. MG. 1(4).

Pereira, B.A. da S., Furtado, P.P., Mendonça, R.C. de \& Rocha, G.I. 1989. Reserva Ecológica do IBGE (Brasília, DF): Aspectos Históricos e Fisiográficos. Bol. FBCN. RJ. 24: 30-43.

, Silva, M. A. \& Mendonça, R. C. 1993. Reserva Ecológica do IBGE, Brasília (DF): Lista das Plantas
Vasculares. Rio de Janeiro: IBGE, Divisão de Geociências do Distrito Federal. 43p. il.

Siqueira, J. C. 1981. Utilização popular das plantas do cerrado. São Paulo, Loyola. 60p.

1988. Plantas Medicinais, Identificação e uso das espécies dos cerrados. $40 \mathrm{p}$.

Sleumer, H. O. 1980. Flacourtiaceae. Flora Neotropica 22: 1-499. il.

1984. Flacourtiaceae. In: Reitz, R. Fl. Ilustr. Catar. 1: 1-95. il.

Torres, R. S. \& Yamamoto, K. 1986. Taxonomia das espécies de Casearia Jacq. (Flacourtiaceae) do Estado de São Paulo. Rev. Bras. Bot. 9: 239-258. il. 